\title{
Illicit drug profiling practices in Finland: An exploratory study about end users' perceptions
}

\author{
Susanna Meola a,b,*, Sami Huhtalab ${ }^{\mathrm{b}}$, Julian Broséus ${ }^{\mathrm{a}}$, Manon Jendly ${ }^{\mathrm{a}}$, Kaisa Jalava ${ }^{\mathrm{a}, \mathrm{b}}$, \\ Laura Aalberg ${ }^{\mathrm{a}, \mathrm{b}}$, Pierre Esseiva ${ }^{\mathrm{a}}$ \\ a School of Criminal Justice, University of Lausanne, Batochime, 1015 Lausanne, Dorigny, Switzerland \\ ${ }^{\mathrm{b}}$ Forensic Laboratory, National Bureau of Investigation, 01301 Vantaa, Finland
}

\section{A R T I C L E I N F O}

\section{Article history:}

Received 30 December 2020

Received in revised form 15 April 2021

Accepted 14 May 2021

Available online 21 May 2021

\section{Keywords:}

Utilization

Usefulness

Illicit drug profiling

Forensic intelligence

Investigation

Evidence

\begin{abstract}
A B S T R A C T
Illicit drug profiling (i.e. chemical and/or physical profiling) to compare and relate illicit drugs samples has been actively used in routine case work at the National Bureau of Investigation (NBI) in Finland. This preliminary and exploratory work reviews NBI's illicit drug profiling practices. Particular emphasis is put on communication of forensic results and how the NBI has promoted the use of forensic data in an intelligence perspective by establishing a case coordination service. Moreover, our study evaluates the comprehension, integration and usefulness of illicit drug profiling from end users' point of view by means of an online survey and face-to-face interviews. Findings are compared with theoretical aspects as described in literature. Results show that in the Finnish context illicit drug profiling is used and useful in the investigation and in court. From end users' perspective, real practical relevance relies in its use as intelligence during the investigation. However, to be truly useful, illicit drug profiling results must be communicated promptly during the investigation, with sufficient clarity and interpreted correctly by end users. Factors influencing the integration of illicit drug profiling in the forensic process are addressed.
\end{abstract}

(C) 2021 Elsevier B.V. All rights reserved.

\section{Introduction}

Forensic science has long been seen as a mean to generate forensic evidence in a probative process rather than as a crime analysis tool furnishing valuable information during the investigation process [1-3]. In the past years, the view has changed and numerous authors have emphasized the contribution of forensic science and the data provided by the latter towards crime analysis and investigation [2].

In the field of illicit drugs ${ }^{1}$ this potential has been widely recognized as well. Analytical methods do not only allow one to identify and to quantify illicit compounds of seized material to support the judicial process, but can also provide additional and even more valuable information (i.e. illicit drug profiling) in an intelligence perspective $[4,5]$.

\footnotetext{
* Corresponding author at: School of Criminal Justice, University of Lausanne, Batochime, 1015 Lausanne, Dorigny, Switzerland.

E-mail address: susanna.meola@outlook.com (S. Meola).

1 Narcotics, psychotropic substances and precursors under international control are called "illicit drugs" throughout this work.
}

The utilization of illicit drug profiling (i.e. chemical and/or physical profiling) to compare and relate illicit drugs samples bears a long history. The first attempt to establish links between illicit drugs was based on physical characteristics (e.g. dimensions, alterations or mold defaults, etc.) of illicitly produced tablets [6]. Since then, important contributions in this field have been made [7] and the importance and value of illicit drug profiling as a law enforcement tool in an intelligence perspective has been widely recognized and discussed. Over the past years, research has mainly focused on the development and improvement of analytical techniques, comparison methodologies and/or decision theories (e.g. threshold and Bayes) for chemical profiling of mainly cocaine, heroin, amphetamine-type stimulants and cannabis [8-21]. Many authors have highlighted the benefits of it during the investigation for tactical and strategic purposes on national and international levels [5,10,12,22-28] and efforts have been made to develop, incorporate and implement it as routine part of the investigation process $[4,5,27,29]$. Less focus has been placed on physical profiling (i.e. physical characteristics of substances and packaging materials) regarding its use in an intelligence perspective [30] even though, it adds fast and valuable information for the investigation. Only few examples assess the practical utilization and usefulness of illicit drug profiling within an investigative process $[4,5,22]$. 
The National Bureau of Investigation's (NBI) Forensic Laboratory in Finland has the advantage of being a centralized laboratory regarding illicit drug analysis and intelligence. This enables nationwide comparison of seized samples, to gain a better understanding of current illicit drug trends within Finland and an easy exchange of information on national and international levels. The establishment of a case coordination center as a crime analysis unit within the Forensic Laboratory represents a change of thinking from forensic science as a pure probative process to a powerful investigative tool. Countries, like Switzerland, that lack a centralized laboratory, harmonized methods between the different laboratories or a crime analysis unit, information provided by illicit drug profiling cannot be easily exchanged and compared between the different jurisdictions. In consequence, the use of such information is limited.

As mentioned above, over the past years, illicit drug profiling research has focused on the development and improvement of analytical techniques and chemometrics for illicit drug profiling for intelligence purposes. Yet, little is known about how the information extracted form illicit drug profiling is exchanged between laboratories and end users (i.e. illicit drug investigators and prosecutors) as well as how it is integrated and used within a criminal justice system. Moreover, its practical relevance from end users' point of view has never been assessed. For the routine use of illicit drug profiling in the investigation process, collaboration between laboratories, coordinators and law enforcement authorities is mandatory. Furthermore, timely and clear communication of results (i.e. highlighted links) and proper interpretation of the information conveyed by the highlighted links is essential, if not the most crucial step in the intelligence cycle [31]. In the authors' knowledge, no research in this field has yet focused on this step or questioned if illicit drug profiling is at all useful for end users and how they understand and exploit such information in practice. Through our study we gained insight about utilization and usefulness of illicit drug profiling within the Finnish criminal justice system from end users' point of view.

In the following section, we provide a brief overview of the contribution of illicit drug profiling in the investigation process and as evidence in court as presented in literature. Moreover, we will describe illicit drug-related activities of the drug-testing unit and case coordination center and illustrate how illicit drug profiling and crime analysis are integrated in the investigative process in Finland. Particular attention will be drawn to the way information is collected, processed and shared by the main actors (i.e. forensic chemists, case coordinators, drug investigators and prosecutors) involved in the forensic workflow [31] of illicit drug cases.

\section{Context}

\subsection{Utilization and usefulness of illicit drug profiling: intelligence vs. evidence}

Esseiva and Margot [32] break down the illicit drug profiling process into two steps:

(1) the extraction of a chemical and/or physical profile (i.e. a subset of sample's chemical or physical characteristics chosen regarding the purpose of the process);

(2) the analysis and interpretation of the provided information.

As the extracted information varies depending on the considered source level (e.g. geographical origin, clandestine laboratory, synthetic pathway, production batch, physical unit, etc.), to establish the chemical/physical profile of the seized substance it is essential to preform proper sampling and selection of a suitable analytical methodology as well as proper interpretation of the results [4,32-34].
This combination of information ultimately results in a forensic intelligence product [1,3] which may be used for political (e.g. national and international control of illicit products, development of policies, etc.), investigative or evidential purposes [32]. In this paper, we focus on the last two frameworks.

Typical judicial procedures, in the field of illicit drugs, require identification and quantification of the seized substance to formally establish the illegality and amount of the substance. Both elements are essential for the justice system to assess the accused's conviction according to the rules of law in force [5]. This represents the traditional forensic process aiming to establish evidence for the court. However, in some cases, investigative units or prosecutors have shown the interest in case-to-case comparisons $^{2}$ to prove whether seized substances in different places or on different persons share a common origin or a dealing act between persons under investigation [4,22,27,32]. In this case, comparison results are added as piece of evidence to be presented in court. Despite these few examples, it is stated by Esseiva and Margot [32] that illicit drug profiling is rarely, if at all, needed for court purposes since more information is required to assess the accused's conviction or to prove a criminal activity. Thus, more importance should be given to its use in an intelligence perspective.

During the investigation the results obtained from illicit drug profiling can be used as intelligence for tactical/operational or strategic purposes (Table 1 ) depending on the context and level in which it is applied $[5,12,22-27]$. A good depiction of the intelligence process can be found in [35].

At a regional level, intelligence may be used more in a tactical way, whereas on national or international levels, it's used more frequently in a strategic way. As discussed in literature the use of illicit drug profiling in a strategic way is only possible if each specimen is systematically analyzed and recorded in a database $[10,22]$. In this case, detailed knowledge about the structure and organization of illicit drug trafficking can be obtained by combining this information with traditional police information [27,32]. Moreover, it is argued that this overview cannot be obtained by case-to-case comparisons, which are used mainly for tactical purposes. However, in the author's opinion, there are no fixed boundaries between tactical and strategic intelligence. For instance, tactical intelligence on different cases can be gathered to establish distribution networks and thus can contribute to an overall strategic view. Conversely, strategic intelligence can point towards specific cases leading to tactical intelligence [36].

Even though numerous studies have shown how illicit drug intelligence in general and illicit drug profiling in particular can be used mainly for investigative purposes, little has been discussed about how end users perceive and actually use this information. Also, it has never been discussed how comparison results are assessed in court as evidence. Therefore, in our opinion, the previous cited two steps need to be completed by a third one:

(3) the communication of the resulting forensic intelligence product to law enforcement officers and prosecutors.

In literature, this step is the least considered and discussed. Yet, it is an essential step, since comparison results have to be provided in a comprehensive way to be effectively and correctly exploited by the end users [31].

\footnotetext{
2 Case-to-case comparison relates to comparison of specimens, from specific cases, confiscated in different places, at different times, on different persons and/or different occasions selected according to traditional police information.
} 
Table 1

Summary of tactical/operational and strategic intelligence as found in literature [5,12,22-27].

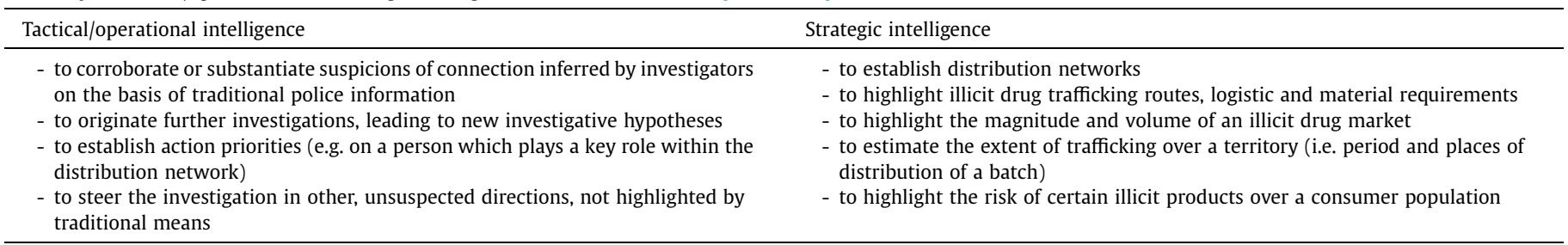

Table 2

Comparison conclusions as reported to investigators and prosecutors (translated from Finnish).

\begin{tabular}{|c|c|}
\hline Conclusion & Meaning \\
\hline Similar & The compared samples are from the same batch manufactured by the same illegal laboratory or from very similar batches. \\
\hline Linked & $\begin{array}{l}\text { The compared samples are from different batches manufactured by the same illegal laboratory or from different illegal laboratories using } \\
\text { identical synthetic pathway. }\end{array}$ \\
\hline Inconclusive & Based on the comparison result no conclusion can be made according to the similarity of the samples or their origin. \\
\hline Different & The compared samples are from different illegal laboratories or manufactured using different synthetic pathways. \\
\hline
\end{tabular}

\subsection{Illicit drug profiling in the drug-testing unit}

The NBI is a nationwide division of the Finnish police. It serves as a center for intelligence activities focusing on serious and organized crimes and for international criminal police cooperation. Finland acts as a transit and market area for the trafficking of illicit drugs. Drug trafficking is therefore of important concern.

Illicit drugs seized in the different jurisdictions are handled and analyzed by the drug-testing unit of NBI's Forensic Laboratory. Besides identification and purity measurements for judicial issues, the drug-testing unit provides case-to-case comparison for amphetamine, methamphetamine and cocaine samples. Database comparisons are performed routinely according to requests and systematically if the amount of the seized substance exceeds pre-set limits. Comparison conclusions for amphetamine profiling at the time of the survey were given to investigators and to prosecutors as shown in Table $2 .^{3}$ On one hand, illicit drug profiling is used for evidential purposes (i.e. in organized crime; where criminal networks have been revealed and prosecuted) and on the other hand, for tactical and strategic purposes on national and international levels (e.g. support investigations, detect and follow drug trends within Finland, etc.).

\subsection{Case coordination center: organization and tasks}

In 2012, the National Bureau of Investigation set up a case coordination center, acting as a crime analysis unit, in which forensic data is centralized, analyzed and redistributed to law enforcement authorities. The tasks of it consist in assisting customers (i.e. investigators and prosecutors), for example in the prioritization of analyses and in coordinating the information flow between the Forensic Laboratory and law enforcement authorities (Fig. 1).

Having access to the laboratory and police database, the case coordination center is able to produce charts visualizing the revealed connections upon request from customers, when series ${ }^{4}$ are highlighted and when database or case-to-case comparisons are conducted. As they can gather and combine forensic data (e.g.

\footnotetext{
3 Collaborative Harmonization of Methods for Profiling of Amphetamine Type Stimulants (CHAMP). Specific Targeted Research Project (STREP) no CIS8-CT-2004502126, 6th Framework Program of the European Community.

4 Several cases are related to one another and build a "big case".
}

\section{Forensic Science System}

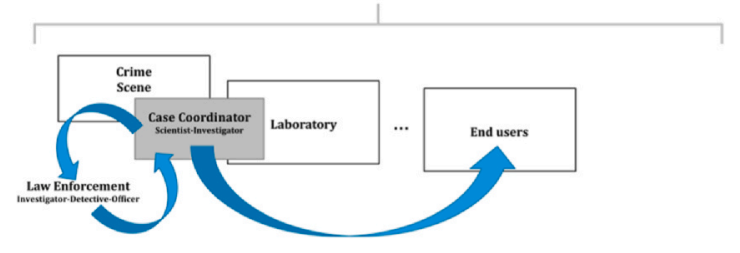

Fig. 1. Visualization of the role of the case coordination center in a forensic science system [37].

fingerprints, DNA, packaging, etc.) with illicit drug profiling data and traditional police data (e.g. circumstantial information), they are able to generate a powerful crime analysis tool and provide support for end users regarding the understanding of the produced intelligence. The case coordination center acts as an intermediary interlocutor between the laboratory which generates data and investigators and prosecutors who finally use the generated information in their decision making. Moreover, communication between the laboratory, the case coordination center and law enforcement authorities is facilitated through the electronic exchange of documents via the police database. The development of such a case coordination center is a step forward to the use of forensic science in an intelligence perspective.

The NBI's Forensic Laboratory, with its drug-testing unit and case coordination center offers the best conditions for exploiting illicit drug intelligence to its full potential. However, little is known about how the shared information is finally integrated in the investigative process and used by their end users as well as its actual practical usefulness [10].

\section{Methodology}

In this exploratory study, the Finnish criminal justice system was considered. To gain insight about how the information produced by illicit drug profiling is perceived and used by investigators and prosecutors dealing with illicit drug cases as well as to evaluate its practical usefulness, an online self-administrated survey was designed and carried out using Webropol 2.0^ software and two faceto-face interviews were conducted [38-40]. 
Table 3

Sample questions from the survey ${ }^{\mathrm{a}}$.

Section Questions

(2) Clarity and interpretation of the comparison conclusions

In your opinion, are the comparison results obtained from the drug-testing unit explicit? Proposed responses: Yes/No/I cannot say

How do you understand the meaning of the comparisons' conclusions (similar, linked, inconclusive, different)?

Please explain how you interpret the comparisons' conclusions.The respondents were invited to explain how they interpret the comparisons' conclusions in order to evaluate whether the meaning of the comparison conclusions is understood and interpreted correctly.

(3) Utilization and usefulness of illicit drug profiling in the investigation ${ }^{\mathrm{b}}$

How did you use comparisons' results in the investigation?'Proposed responses: on its own in order to relate two (or more cases)/combined with other case related information (e.g. fingerprints, DNA, etc.) to relate two (or more cases)/other way, how?

For what purpose, did you use comparisons' results in the investigation? ${ }^{\mathrm{C}}$ Proposed responses: for case-to-case comparison/in an intelligence-led approach using database requests/other purpose, which one?

What would be (on average) a suitable maximal delivery time for comparisons' results, if the results will be used for investigation issues?

Proposed responses: 14 days/90 days/other, how many days?/I cannot say Similar questions were asked for obtaining information of the utilization and usefulness of illicit drug profiling in court.

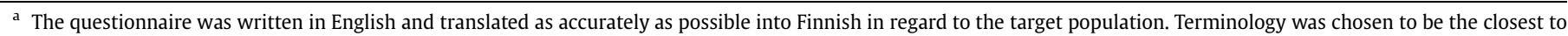

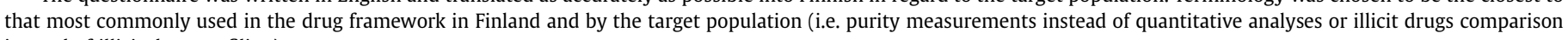
instead of illicit drug profiling).

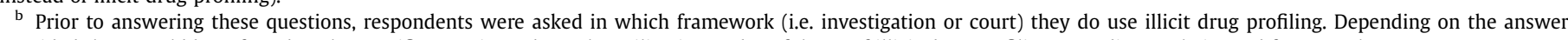
provided they would be referred to the specific questions about the utilization and usefulness of illicit drug profiling according to their used framework.

c Respondents were invited to choose what applied and several answers could be given.
}

The interviews were complementary to the online survey and were conducted for validation purposes and to complete and enhance the understanding of the data collected via the online survey. As the interviews were held one week before the launch of the online survey, it could be verified that the questions and proposed answer options were appropriate to the studied context.

The target population included professionals actively involved with illicit drug cases (i.e. police investigators and prosecutors). These professionals were chosen based on their knowledge and involvement related to illicit drug cases and were divided in the following categories: investigation chiefs, illicit drug investigators, investigators, ${ }^{5}$ technical investigators and prosecutors.

The online survey was accessible to respondents via a link. It was sent by e-mail to 18 of the most active investigation chiefs in the illicit drug field and to 25 group leaders of technical centers (CSI units) of each police area and to 29 prosecutors working across Finland and who are actively involved in the prosecution of illicit drug and organized crime cases. The investigation chiefs and group leaders were asked to forward the e-mail with the link to all relevant person, such as illicit drug investigators, investigators and technical investigators involved with illicit drug cases and to send us back the number of forwarded e-mails, in order to estimate the response rate. Unfortunately, despite our demand, no such information was returned to the authors. However, considering that each investigation or technical unit consists of 3-20 persons and that prosecutor's offices have no such teams, we can estimate the target population to be about 300 persons. We address this major limitation of our study further in this article.

The questionnaire consisted of 18 questions intended to gather information regarding respondents' (1) biographical data such as gender, age, occupation, professional experience, training and education; (2) comprehension and interpretation of illicit drug profiling results; (3) practices about the utilization and usefulness of illicit drug profiling according to their application framework and (4)

\footnotetext{
${ }^{5}$ In some regions there may not be a specific drug unit but only a general unit with investigators dealing with all sorts of cases, including illicit drug cases, thus we included the category "investigator".
}

opinion about the survey (e.g. survey's length, question's clarity and improvement suggestions). ${ }^{6}$ After the biographical data section participants were asked whether they have ever needed or used illicit drug profiling during the investigation or in court. Respondents answering negatively to this filtering question were directly forwarded to the end of the questionnaire since they were not considered as belonging to the relevant population. ${ }^{7}$ Table 3 provides an example of the questions used in Sections (2) and (3) of the questionnaire.

All questions except three, ${ }^{8}$ were structured following a closed response format (e.g. one-selection, multiple-choice, etc.) which enabled more uniform responses, facilitating their analysis. Where it was needed, partially closed questions (integration of the option "other...") were used as well. The aim was to identify if some options had been overlooked by letting respondents propose an answer. ${ }^{9}$

The questionnaire was sent to personnel from the drug-testing unit $(n=3)$ and of the customer service $(n=2)$ for tryout. This was done to evaluate whether the structure, content and relevance of the questions (content validity) were appropriate to the study's purpose and to assess eventual technical/functional problems. Modifications were made according to feedback received form these in-house test groups. The survey was further pre-tested by sending it to one person representing the target population $(n=1$, illicit drug investigator $)^{10}$ to avoid reducing the study population and to ensure that it provides reliable and valid data [39-41]. The results of this pre-test enabled to make some adjustments and to adapt the survey to the target population (i.e. deletion and reformulation of questions,

\footnotetext{
6 To improve the quality of the survey for future use.

7 This filtering question was integrated so that only relevant members of the target population would have to answer to specific questions about the clarity and interpretation of the profiling conclusions and the utilization and usefulness of illicit drug profiling according to the application framework (investigation/court).

8 Three open-ended questions were used to give respondents the opportunity to express themselves.

9 Only if answers are given they are reported in the result section.

10 Due to uncertainties regarding the final size of the study population, only one person of the target population could be chosen for the pre-test.
} 
correction of terms and of function settings) as well as to determine the time required to complete the survey. ${ }^{11}$

The answers from the self-administrated survey were analyzed using the Webropol 2.0๔ interface and Microsoft ${ }^{\circledR}$ Excel (2010). Descriptive statistics have been conducted and completed by the data collected from the interviews. Findings are put in comparison with theoretical aspects about the utilization and usefulness of illicit drug profiling as described in literature.

Sixty-six questionnaires $(n=66)$ were returned. Considering the estimated target population of 300 persons, this corresponds to a response rate of about $22 \%$. Of the sixty-six participants twenty answered $(n=20)$ negatively to the filtering question resulting in forty-six $(n=46)$ relevant respondents. According to their occupation this corresponds to the following distribution: 16 illicit drug investigators $(35 \%)^{12} ; 10$ investigation chiefs (22\%); 10 prosecutors (22\%); 7 technical investigators (15\%) and 3 investigators (6\%).

In addition to the online survey, face-to-face interviews were carried out in a semi-directive way, based on the methodology proposed by Beaud and Weber [42], with the chief of one drug investigation team of the Drug and Organized crime division of Helsinki's police department and a prosecutor involved mainly in the prosecution of illicit drug and organized crime cases. They both actively participate in the investigation and prosecution processes of illicit drug cases and were suggested and recruited via e-mail by the drug-testing unit's personnel. Compared to self-administered surveys, interviews permit going into details and allow depicting the opinion and experience of the of interviewees [43]. The aim was to obtain the point of view about the survey's topics of investigators and prosecutors involved in different stages of the forensic workflow of illicit drug cases rather than a comprehensive view within a target group [43]. Questions were based on the same major subjects as used for the online survey and analyzed following a thematic analysis $[44,45]$.

\subsection{Limitations and difficulties}

Some limitations and difficulties in the methodology have been addressed previously but some others were encountered during the creation of the survey.

First, the main limitation of our study relies in the impossibility to assess the exact total number of professionals to whom the survey was sent out. As mentioned previously, the demanded investigation chiefs' and group leaders' feedback about the number of forwarded e-mails was never returned to the authors. Despite this limitation, the number of participants was in the opinion of the drug-testing unit's personnel higher than expected.

Second, the survey was launched during the period of national holidays in Finland which may have had an impact on the number of respondents, since members of the target population might have been on holidays.

Third, the number of respondents to the survey and the number of interviewees is rather low and thus, the results have to be interpreted carefully. However, they do highlight some interesting points on which further research can be based.

Fourth, according to Thomas [44], the trustworthiness of the data analysis should be assessed by a second person (i.e. coding consistency checks). Even though this was not performed in this survey, it was not seen as a major problem as the interviews were complementary to the online survey.

Lastly, translation of the English version accurately to Finnish slowed down the survey creation process. Sentences had to have the same meaning and words had to be carefully chosen. It is known that

\footnotetext{
11 The expected time required for completing the survey was approximately $10 \mathrm{~min}$.

12 The percentage values presented are rounded up.
}

the wording of phrases can have an impact on how the respondents will answer [46]. The time accorded for the creation of the survey along with translations limited the number and availability of persons that could be interviewed. Oftentimes, they were discouraged by the fact that the interview was conducted in English. However, as the aim of the interviews was not to achieve saturation in the responses and generalization theories, this was not considered as a problem.

\section{Results and discussion}

Forensic laboratories serving law enforcement authorities have to consider customers' requirements and the presented forensic questions [31]. Analytical techniques and methods have to be developed based on a customer's demand in order to provide the required information. Moreover, law enforcement authorities have to be available to support the integration and use of such information in the investigative process [25]. A close collaboration between forensic scientists, crime analysts and law enforcement authorities is therefore of crucial importance.

As previously mentioned, the NBI's Forensic Laboratory has the advantage of being a centralized laboratory in both, routine analysis and drug intelligence while also being part of the police organization. Moreover, the NBI has created, with the establishment of the case coordination center, a crime analysis unit which has the possibility to use illicit drug profiling to generate timely and accurate intelligence and to provide insight into criminal activity. As a result, the provided intelligence enables law enforcement investigators to be more proactive than reactive $[2,8,35]$. The drug-testing unit and the case coordination center are an integral part of the investigative and intelligence process not working for, but rather with law enforcement authorities. Consequently, information exchange with law enforcement authorities is eased and more efficient, especially because there are no barriers or bureaucracy slowing it down. The combination of NBI's drug-testing unit and case coordination center demonstrate the willingness and ability to process, analyze, collect, combine and communicate results obtained from illicit drug profiling for tactical and strategic intelligence to law enforcement authorities on national and international levels.

\subsection{Clarity and interpretation of comparison results}

A factor influencing the proper utilization of illicit drug profiling is the manner in which results are presented and communicated. Comparison results have to answer the reported forensic question [31], be explained with sufficient clarity and be presented in a comprehensible form to investigative units and prosecutors to be effectively used by them. Conversely, end users have to correctly understand and integrate the information obtained by illicit drug profiling. If the information is used erroneously it can discredit the whole profiling process [32]. Therefore, comparison results and their meaning (i.e. "what does the highlighted connection or "link" mean?") have to be explained thoroughly and uncertainties have to be expressed clearly enough to facilitate effective police action [27]. However, the meaning of the highlighted connections, the evaluation and strength of such correspondence as well as link management and information exchange with police forces have seldom been discussed in literature, but is essential for promoting a more systematic utilization of illicit drug profiling by law enforcement authorities [22,47,48].

The combination of these requirements is necessary if a correct integration and use of illicit drug profiling in a criminal justice system is aimed, which however demands a close collaboration between all the actors involved.

Therefore, it was of interest to evaluate this aspect through the survey. Results according to the clarity and interpretation of illicit drug profiling conclusions as given by the forensic laboratory are presented 
Table 4

Respondents' distribution regarding the clarity of illicit drug profiling conclusions as given by the drug-testing unit according to their occupation $\left(\mathrm{n}=45^{13}\right.$ ).

\begin{tabular}{|c|c|c|c|c|c|c|c|c|c|c|c|c|}
\hline \multirow[t]{2}{*}{ CLARITY OF THE CONCLUSIONS } & \multicolumn{2}{|c|}{ Investigation chiefs } & \multicolumn{2}{|c|}{$\begin{array}{l}\text { Illicit drug } \\
\text { investigators }\end{array}$} & \multicolumn{2}{|c|}{ Investigators } & \multicolumn{2}{|c|}{$\begin{array}{l}\text { Technical } \\
\text { investigators }\end{array}$} & \multicolumn{2}{|c|}{ Prosecutors } & \multicolumn{2}{|l|}{ Total } \\
\hline & Number & $\%$ & Number & $\%$ & Number & $\%$ & Number & $\%$ & Number & $\%$ & Number & $\%$ \\
\hline Yes & 10 & 100 & 14 & 87.5 & 3 & 100 & 5 & 83.3 & 7 & 70 & 39 & 86.7 \\
\hline No & 0 & 0 & 1 & 6.3 & 0 & 0 & 0 & 0 & 2 & 20 & 3 & 6.5 \\
\hline \multirow[t]{2}{*}{ I cannot say } & 0 & 0 & 1 & 6.3 & 0 & 0 & 1 & 16.7 & 1 & 10 & 3 & 6.5 \\
\hline & 10 & 100 & 16 & 100 & 3 & 100 & 6 & 100 & 10 & 100 & 45 & 100 \\
\hline
\end{tabular}

Table 5

Respondents' distribution regarding the interpretation of illicit drug profiling conclusions as given by the drug-testing unit according to their occupation ( $\mathrm{n}=46$ ).

\begin{tabular}{|c|c|c|c|c|c|c|c|c|c|c|c|c|}
\hline \multirow[t]{2}{*}{$\begin{array}{l}\text { INTERPRETATION OF THE } \\
\text { CONCLUSIONS }\end{array}$} & \multicolumn{2}{|c|}{ Investigation chiefs } & \multicolumn{2}{|c|}{$\begin{array}{l}\text { Illicit drug } \\
\text { investigators }\end{array}$} & \multicolumn{2}{|c|}{ Investigators } & \multicolumn{2}{|c|}{$\begin{array}{l}\text { Technical } \\
\text { investigators }\end{array}$} & \multicolumn{2}{|c|}{ Prosecutors } & \multicolumn{2}{|l|}{ Total } \\
\hline & Number & $\%$ & Number & $\%$ & Number & $\%$ & Number & $\%$ & Number & $\%$ & Number & $\%$ \\
\hline Answer given & 7 & 70 & 11 & 87.5 & 1 & 33.3 & 2 & 28.6 & 9 & 90 & 30 & 65.2 \\
\hline \multirow[t]{2}{*}{ No answer given } & 3 & 30 & 5 & 6.3 & 2 & 67.7 & 5 & 71.4 & 1 & 10 & 16 & 34.8 \\
\hline & 10 & 100 & 16 & 100 & 3 & 100 & 7 & 100 & 10 & 100 & 46 & 100 \\
\hline
\end{tabular}

in Tables 4 and 5. For the majority of the respondents $(n=39,87 \%)$ the comparison conclusions are explicit. However, the analysis of the openended answers shows that there is still some confusion regarding how the conclusions "similar" and "linked" should be interpreted.

It was not only of interest to assess whether the profiling conclusions as shown in Table 2 are clear or not, but also to see whether the interpretation given by end users is correct. $65 \%(n=30)$ of the respondents answered to the open-ended question regarding the interpretation of illicit drug profiling results (Table 5).

Despite the fact that the given interpretations about the profiling conclusions are correct, some given answers highlight the need to enhance the comprehensibility of them. In addition, answers given by prosecutors highlight the value given to illicit drug profiling conclusions (i.e. value of "linked" vs. "similar") as reported by the forensic laboratory (Table 2). For the nine prosecutors that answered the open-ended question, the conclusion "linked" is useful for directing the investigation. However, in court only the conclusion "similar" is meaningful as evidence. From the prosecutors' answers, it seems that the conclusion "similar" is associated with less uncertainty than the conclusion "linked", which, to them, is not considered meaningful in court. Comparable statements have been made by the interviewed illicit drug investigator. He considers the conclusion "similar" as a "stronger link" in comparison to the conclusion "linked". For the latter, he explains that additional information is needed to support the highlighted relationship.

As stated by Morelato, et al. [27], evidence can be considered as one type of intelligence, which is used by the judge or jury to form a conviction. However, risk and uncertainties associated with court's decisions have to be minimal and the information conveyed has to be comprehensible for all the practitioners. Therefore, the answers given by the prosecutors are not surprising. However, comments made by the respondents and the interviewee show that the value of comparison conclusions is not well understood, as addressed by Reddick [25]. The latter states that amongst some law enforcement officers, there is a misconception that a comparison is of value only if the conclusion is that the compared samples are "similar". ${ }^{14}$

This emphasizes the importance to communicate the highlighted connection in a comprehensive way according to its context (i.e. case specific and background information). In the authors' opinion, both conclusions can furnish valuable information. The conclusion

\footnotetext{
13 One technical investigator did not answer this question.

14 "Similar" meaning that the compared samples are coming from the same batch produced by the same laboratory or from very similar batches.
}

"linked" can be as important (i.e. "strong") as the conclusion "similar", especially to the investigation but also in court. ${ }^{15}$ Therefore, as proposed also by the interviewed drug investigator, further education, training or seminars discussing this aspect are necessary and should be considered by the forensic laboratory.

\subsection{Application framework of illicit drug profiling}

How and for what purpose illicit drug profiling is used, may vary according the framework in which it is applied.

Results highlight that illicit drug profiling is used to support the investigation. Namely, to confirm suspicions that arise throughout the course of the investigation and/or to orientate the investigation towards unsuspected relationships by means of case-to-case comparison and database requests. Findings reflect the Finnish investigative process, where results obtained from illicit drug profiling are mainly used for tactical purposes at a regional level and for strategic purposes on national and international levels. In some cases, illicit drug profiling is used for evidential purposes and added to the pre-trial document meant for the prosecutor to be used as evidence in court.

As shown in Table 6, 63\% of the respondents reported using comparison results for the investigation and 37\% reported their use in court. All of the prosecutors have reported, as we expected, to have used the results obtained from illicit drug profiling in court $(n=10,100 \%)$. However, investigators (except for technical investigators) have reported using the obtained results in both the investigation and in court, despite the fact that the question was formulated in a personal way. ${ }^{16}$ This filtering question was set to direct respondents to the specific questions about utilization and usefulness in their application framework. Our assumption was that all police personnel would answer "in investigation" and prosecutors "in court", respectively. Interestingly, this was not the case. Only a minority of the investigators $(n=7)$ answered using comparison results in court.

One reason could be that the question has not been answered in a personal way (i.e. where they use illicit drug profiling in their dayto-day work). According to general comments about the survey, an illicit drug investigator, who answered "in court", stated that he

\footnotetext{
15 Even if the conclusion "linked" may let suppose a greater degree of uncertainty, it can add valuable information. For instance, when proving drug trafficking between the wholesaler and the dealer (presence of cutting agents).

16 Do you use comparisons results in the investigation or in court?
} 
Table 6

Respondents' distribution regarding the application framework of illicit drug profiling according to the respondents' occupation ( $\mathrm{n}=46$ ).

\begin{tabular}{|c|c|c|c|c|c|c|c|c|c|c|c|c|}
\hline \multirow[t]{2}{*}{ APPLICATION FRAMEWORK } & \multicolumn{2}{|c|}{ Investigation chiefs } & \multicolumn{2}{|c|}{$\begin{array}{l}\text { Illicit drug } \\
\text { investigators }\end{array}$} & \multicolumn{2}{|c|}{ Investigators } & \multicolumn{2}{|c|}{$\begin{array}{l}\text { Technical } \\
\text { investigators }\end{array}$} & \multicolumn{2}{|c|}{ Prosecutors } & \multicolumn{2}{|l|}{ Total } \\
\hline & Number & $\%$ & Number & $\%$ & Number & $\%$ & Number & $\%$ & Number & $\%$ & Number & $\%$ \\
\hline in the investigation & 9 & 90 & 12 & 75 & 1 & 33.3 & 7 & 100 & 0 & 0 & 29 & 63 \\
\hline \multirow{2}{*}{ in court } & 1 & 10 & 4 & 25 & 2 & 67.7 & 0 & 0 & 10 & 10 & 17 & 37 \\
\hline & 10 & 100 & 16 & 100 & 3 & 100 & 7 & 100 & 10 & 100 & 46 & 100 \\
\hline
\end{tabular}

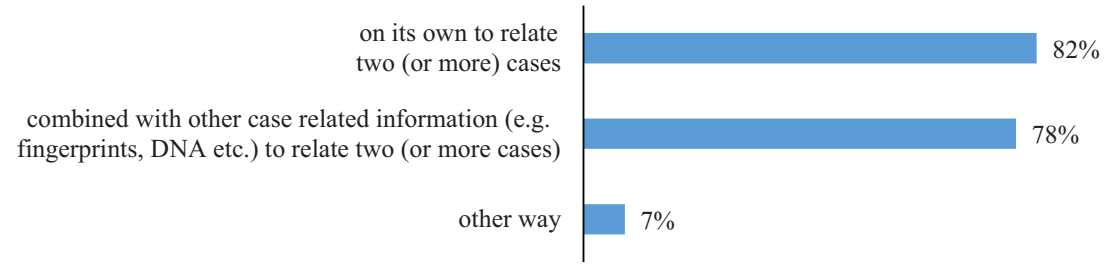

Fig. 2. Multiple choice question about the utilization of illicit drug profiling in the investigation with $\mathrm{n}=27$ respondents. ${ }^{17}$

would have preferred to choose both answers for this question, because illicit drug profiling is used in both frameworks. However, the third option (i.e. both) was not included as it was a filtering question. According to the interviewed prosecutor, police units investigate into the case and send the pre-trial document to the prosecutor once the investigation is finished. Only then, will the prosecutor get acquainted in detail with the case files. Therefore, investigators might have preferred to answer "in court" rather than "in the investigation" because they are either aware that the reported information is used in court as well or because they are focused on gathering evidence for the court.

\subsection{Utilization and usefulness of illicit drug profiling in the investigation}

Fig. 2 shows respondents' distribution regarding how they used illicit drug profiling in the investigation framework. Twenty-two respondents have reported that they did use the results obtained from illicit drug profiling on their own $(n=22,82 \%)$ and twenty-one have reported that they did use them combined with other case related information $(n=21,78 \%)$. Two illicit drug investigators answered using illicit drug profiling in other ways, namely for identifying a distributor or distribution network (strategic intelligence) and to steer the investigation (tactical/operational intelligence). However, these answers highlight more why illicit drug profiling is used rather than how it is used.

It can be deciphered from the interviewed illicit drug investigator's explanations, that how illicit drug profiling is used really case if the information given by illicit drug profiling is not combined with other sources of information (e.g. surveillance data).

As presented by Esseiva et al. [22] and shown in the previous sections of this paper, these findings reflect that illicit drug profiling can be used at any stage of the investigation process. The results can be used on their own as the starting point for further investigations about the highlighted relationship or as one more element confirming the pre-existing connection.

Fig. 3 shows respondents' distribution regarding for what purpose they used illicit drug profiling in the investigation. The aim of this question was to evaluate whether illicit drug profiling is used solely to connect current cases under investigation to each other (case-to case comparison) or to find connections between current cases and cases stored in a database (database comparison). The majority of the respondents have reported that they did use comparison results to investigate between cases (case-to-case comparison) ( $n=23,82 \%)$. Nineteen respondents have reported to have used it to guide the investigation ( $n=19,68 \%$ ) (database comparison) and four respondents have reported to have used it for other purposes $(n=4,14 \%)$. Three of the four other suggested purposes highlight the use of comparison results in a strategic way. ${ }^{18}$

The requests that the forensic laboratory receives from the investigative units are mainly to compare cases, which have been preselected by them based on traditional police information. It may be a comparison between current cases under investigation or between new cases and old ones (i.e. case-to-case comparisons) not solely for evidential purposes but for intelligence purposes, as well. Database comparisons are made systematically by the drug-testing

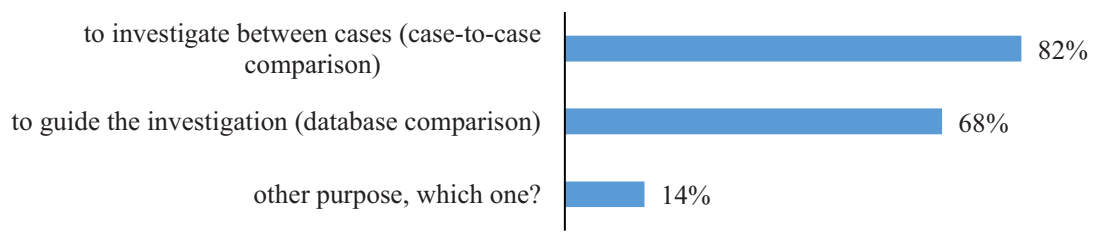

Fig. 3. Multiple choice question about the usefulness of illicit drug profiling in the investigation with $\mathrm{n}=28$ respondents. ${ }^{19}$

depends on the case at hand. In his team, illicit drug profiling is mostly used on its own to steer the investigation. Based on the highlighted information they try to determine, by other means, if there are other connections. Occasionally, they also have cases where illicit drug profiling supports what they have already found. However, the investigator also points out, that it is hard to build a

\footnotetext{
17 One technical investigator and one investigator did not answer this question.

18 Given answers: to highlight import and distribution routes / to localise the wholesaler / to estimate how much of the seized drug has ended up on the street market / to direct the investigation, comparison results have rarely a judicial meaning.

19 One technical investigator did not answer this question.
} 
unit if the seized illicit drug exceeds a pre-set weight limit. This automatic profiling criteria is exceeded in approximately $30 \%$ of annually analyzed specimens (900-1000 samples annually). Thus, it is possible that the samples, for which the comparison analysis is asked, are already stored in the database.

There are some differences between asking a case-to-case comparison and database comparison. In the first framework, the comparison is guided by traditional police information or based on suspicion. Whereas in the second framework, comparison to the database can highlight unsuspected connections, which were not previously considered or known. ${ }^{20}$ Furthermore, the information obtained by case-to-case comparison and/or database comparison can be used in a tactical way. On the contrary, only systematic collection of profiling data into a database makes comprehensive database comparisons possible and allows to gain information, for instance, about the illicit drug market or to estimate the extent of trafficking over a territory (i.e. time period and location of distribution of a batch) and thus, to be used for strategic purposes.

According to the interviewed illicit drug investigator's practice, illicit drug profiling is used for tactical (i.e. confirm and support suspicions) and strategic purposes (i.e. highlight distribution networks) based on case-to-case comparisons.

Thus, case-to-case comparisons should not be reduced to the sole purpose of producing evidence for the court. Of course, all these comparisons generate some kind information, but the difference between their use for investigative purposes (information becomes intelligence) and for judicial purposes (information becomes evidence) has to be well understood $[13,27]$. Furthermore, case-to-case comparisons, when collated, can contribute to strategic intelligence as shown by Broséus et al., [36].

A factor, which has significant influence on the utilization and usefulness of illicit drug profiling when used in an investigative context is - time. As explained by Morelato et al. [27], the criminal environment of interest for investigators is a micro-level (local or punctual) where investigators are more operational and focused on cases that are under investigation. Illicit drug profiling is used then for tactical purposes to support them in taking case-specific actions and decisions. Therefore, rapid responses are essential otherwise its tactical usefulness is lost [5]. Strategic intelligence, compared to tactical intelligence, may accommodate delays in information availability more readily.

Results from the survey and the interview with the illicit drug investigator reflect what is stated in literature [5,27]. Nineteen of twenty-nine respondents $(n=19,66 \%)$ reported that 14 days, on average, would be a suitable maximal delivery time for illicit drug profiling results when used in the investigation. Nine respondents $(n=9,31 \%)$ did suggest other suitable maximal delivery times ranging from 3 days to 60 days $^{21}$ and one respondent $(n=1,3 \%)$ reported "I cannot say" in response to a suitable maximal delivery time.

For cases handled by the interviewed illicit drug investigator, the approximate investigation time is between two and two and a half months. Since it does not constitute a long period, the profiling results should be received relatively early during the investigation, as explained by the interviewee. If the results are received at the end of the investigation, then the results may be irrelevant to the investigation but can still be used as piece of evidence in court. However, he emphasized that illicit drug profiling is more useful during the investigation than for evidential purposes in court.

\footnotetext{
20 For instance, in the case where drugs are found in the forest or in a car stopped by the police, comparison to the database may highlight connection to previous cases. This information can then steer the investigation in some direction and to a reduced number of persons.

2130 and 7 days have been given by $n=2$ respondents, respectively.
}

Moreover, in his investigations, illicit drug profiling has been used mainly for tactical purposes. Thus, rapid responses are essential because decisions regarding further actions have to be made quickly. If the process takes too much time, comparison results may be renounced, as stated by the interviewed drug investigator.

As it can be seen from the results, especially for tactical purposes during the investigation, the intelligence product is useless if not communicated in a timely fashion.

\subsection{Utilization and usefulness of illicit drug profiling in court $^{22}$}

As discussed in Section 2, the first step in the judicial process in the field of illicit drugs consists in the determination of the composition of the seized specimen to formally establish that the substance is an illegal product. Second, the determination of the purity of the illicit substance is required. According to Esseiva and Margot [32] illicit drug profiling is rarely (if at all) needed for court purposes since the provided information will usually lead to arrests and further seizures of illicit material, which is evidence of criminal activities in itself. Thus, major importance is given to its use in an intelligence perspective.

However, as shown in Figs. 4 and 5, the majority of the prosecutors reported to have used comparison results as evidence combined with other case related information $(n=9,90 \%)$ and all of them reported to have used the comparison results to prove that specific cases are related $(n=10,100 \%)$.

In general, when comparison results are used in court, the attention is focused on specific cases under investigation and several pieces of evidence have to be gathered together to convict someone for a specific offence. The results of the survey reveal this general perception of the utilization of drug profiling in court as stated by many authors [27,32].

Explanations given by the interviewees help to nuance these results. As stated by the interviewed illicit drug investigator, comparison results are one piece of evidence among others. How they are used in court depends on the case and the sought proof, as explained by both interviewees. For instance, if it is sought to prove illicit drug trafficking, comparison results used on their own are not enough for evidential purposes but have to be considered with other pieces of evidence. But, if it is sought to know whether the compared samples share a common origin, illicit drug profiling can be used on its own as evidence. If a connection between the seizures is highlighted it will affect the classification of the offence for which the person will be prosecuted.

For instance, person $\mathbf{A}$ is caught with $90 \mathrm{~g}^{23}$ of an illegal substance (amphetamine). In person B's apartment, $20 \mathrm{~g}$ of amphetamine is found. $\mathbf{A}$ is suspected to have sold the $20 \mathrm{~g}$ of amphetamine to $\mathbf{B}$. In this case, as explained by the prosecutor, it was sought to know whether the compared samples share a common origin and to prove drug trafficking. Illicit drug profiling highlighted that the samples were "similar". Consequently, it could be shown that the person A possessed in total $110 \mathrm{~g}$ of amphetamine and was convicted for the possession of a larger amount than what was seized on him. However, to prove that he had sold the substance to $\mathbf{B}$, some more evidence highlighting the selling act was required.

This example helps to understand how illicit drug profiling can be used for evidential purposes in court. In literature, it has never

\footnotetext{
22 Since it was sought to gain an insight about the utilization and usefulness of illicit drug profiling in court by prosecutors, the answers of seven respondents have not been considered (Table 6, p. 14). Thus, the statistics have been conducted on the remaining ten respondents (i.e. prosecutors).

$2390 \mathrm{~g}$ corresponds to the gross weight of the seizure; the Finnish law, distinguishes normal narcotics offence and aggravated narcotics offence based on the total gross weight of the seizure. For amphetamine, the limit is set to $100 \mathrm{~g}$. Above this limit, the offence is considered as being an aggravated narcotics offence.
} 


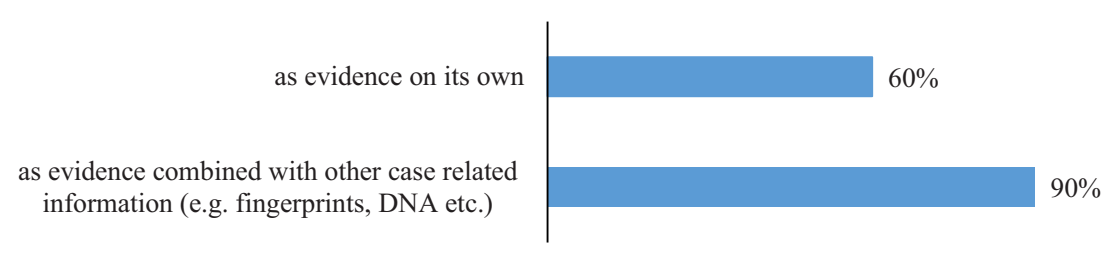

Fig. 4. Multiple choice question about the utilization of illicit drug profiling in court with $\mathrm{n}=10$ respondents.

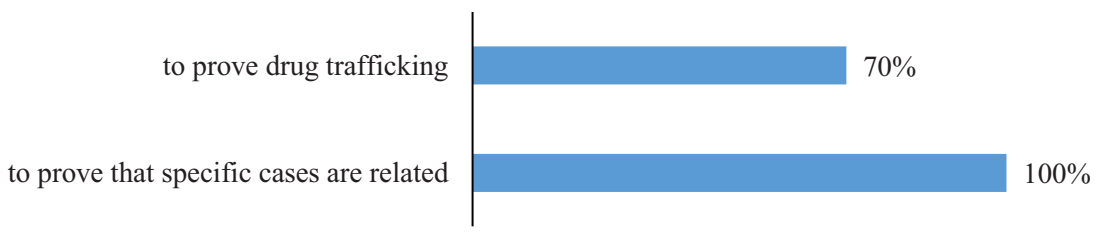

Fig. 5. Multiple choice question about the usefulness of illicit drug profiling in court with $n=10$ respondents.

been discussed how this information is assessed in court as evidence from the practitioners' point of view. As stated by the interviewed prosecutor, the evaluation of comparison results depends on the case and the judge (i.e. what kind of "weight" they put on every piece of evidence). When pre-trial documents include comparison results, presented as evidence in court, judges cannot ignore them as such and are always considered. The same statement was made by the illicit drug investigator. However, the probative value may differ according to what is sought to prove. According to the prosecutor's experience, illicit drug profiling is very important and of great value when dealing with organized criminal groups. As requirements to prove this kind of serious offence are extremely high, comparisons results add dependable and valuable information. For instance, it can be proven by means of illicit drug profiling results that suspected persons are working as a group or that a group exists behind the criminal activities. However, all the pieces of the puzzle are needed to see the whole picture and thus, all case related information has to be combined together. Yet, for both interviewees illicit drug profiling adds more valuable information during the investigation than in court, as it can be used for tactical purposes.

\section{Conclusion}

This preliminary and exploratory work reviewed NBI's illicit drug profiling practices. Particular emphasis was put on communication of forensic results and how NBI has promoted the use of forensic data by establishing an intelligence-led case coordination center. The creation of the case coordination center, able to generate timely and accurate intelligence, represents a change of thinking from forensic science as a pure probative process to a powerful investigative tool and a step forward to the use of illicit drug profiling in an intelligence perspective.

Establishing a chemical/physical profile and highlighting links between seizures is only one part of the forensic process. Thus, by means of an online survey and face-to-face interviews we evaluated the comprehension, integration and use of illicit drug profiling from end users' point of view in Finland. Findings show, that to be truly useful, illicit drug profiling results have to be communicated with sufficient clarity, promptly during the investigation, and the meaning of the comparison conclusions has to be well understood by end users. Moreover, illicit drug profiling is applied in both, investigation and court. During the investigation, it is used on its own and/or combined with other case related information for tactical and strategical purposes. Despite what is generally stated in literature, illicit drug profiling results are used for evidential purposes in court, as well. However, the value given to illicit drug profiling depends on the case and on the activities, it is used to prove. Finally, results highlight that investigation benefits the most from illicit drug profiling.

Nevertheless, even when all these criteria are fulfilled, the lack of human and financial resources can slow down the utilization of illicit drug profiling. These concerns may set limitations to profiling activities and cause delays, increase costs and the risk that such information is renounced. Switzerland - as it might be the case for other countries - faces, compared to Finland, major problems limiting the practical use of illicit drug profiling, which have been identified as the following; i) lack of a centralized structure (i.e. regional or national laboratory and/or coordination center) or a network of laboratories using harmonized methods, ii) challenges to allocate financial and human resources, iii) time required to the treatment of traditional police information and to the prioritization of analysis of other traces (e.g. fingerprints, DNA, etc.), iv) end users' readiness and motivation to support the integration and use of illicit drug profiling and illicit drug intelligence.

In the authors opinion, despite the many efforts done by the School of Criminal Justice (ESC) at the University of Lausanne to promote the routine use of illicit drug profiling in the investigative process $[5,21,22]$, it is still poorly used in an intelligence perspective on regional and national levels. This may be due to the fact that forensic science is still perceived, in this field, as a pure probative process and/or that investigators and prosecutors have not yet recognized the usefulness of illicit drug profiling as an important investigative tool.

Illicit drug profiling is a complex concept and may not be intuitively understandable for law enforcement authorities. Despite this complexity, it is necessary to demonstrate how useful this information can be in the investigative process. For illicit drug intelligence (i.e. illicit drug profiling) to be properly integrated and used by end users, it may be of advantage to create, like in Finland, a case coordination center or crime analysis unit that gathers such information and/or to have forensic scientists who are able to interpret and communicate with sufficient clarity the produced intelligence. A close collaboration between forensic scientists, crime analysts and law enforcement authorities is therefore, of crucial importance.

Through this paper, it is hoped that the forensic community (e.g. investigators, prosecutors, forensic scientists, etc.) can gain a greater awareness of the practical usefulness of illicit drug profiling in an intelligence perspective. 


\section{CRediT Authorship Contribution Statement}

Susanna Meola: Conceptualization, Methodology, Investigation, Formal analysis, Data Curation, Writing - original draft preparation, review \& editing. Sami Huhtala: Resources, Supervision, Project administration, Writing - review \& editing. Julian Broseus: Supervision, Project administration, Writing - review \& editing. Manon Jendly: Writing - review \& editing. Kaisa Jalava: Writing review \& editing. Laura Aalberg: Writing - review \& editing. Pierre Esseiva: Supervision, Writing - review \& editing.

\section{Acknowledgement}

This research has been conducted at the National Bureau of Investigation in Vantaa (Finland) and has been presented at the 20th ENFSI Drugs Working Group Meeting in Espoo (Finland). For this opportunity, the first author acknowledges, Robin Lardot, Head of the National Bureau of Investigation, Erkki Sippola, Head of the Forensic Laboratory and the Erasmus Program of the University of Lausanne. The first author would like to acknowledge especially NBI's Chemical Examinations' personnel and anyone who has contributed to the realization of this work as well as all the survey respondents and interviewees. This research did not receive any specific grant from funding agencies in the public, commercial, or not-for-profit sectors.

\section{References}

[1] O. Ribaux, A. Girod, S.J. Walsh, P. Margot, S. Mizrahi, V. Clivaz, Forensic intelligence and crime analysis, Law Probab. Risk 2 (2003) 47-60, https://doi.org/ $10.1093 / \mathrm{lpr} / 2.1 .47$

[2] O. Ribaux, S.J. Walsh, P. Margot, The contribution of forensic science to crime analysis and investigation: forensic intelligence, Forensic Sci. Int. 156 (2006) 171-181, https://doi.org/10.1016/j.forsciint.2004.12.028

[3] O. Ribaux, A. Baylon, C. Roux, O. Delémont, E. Lock, C. Zingg, P. Margot, Intelligence-led crime scene processing. Part I: forensic intelligence, Forensic Sci. Int. 195 (2010) 10-16, https://doi.org/10.1016/j.forsciint.2009.10.027

[4] J. Broséus, S. Huhtala, P. Esseiva, First systematic chemical profiling of cocaine police seizures in Finland in the framework of an intelligence-led approach, Forensic Sci. Int. 251 (2015) 87-94, https://doi.org/10.1016/j.forsciint.2015.03. 026

[5] S. Ioset, P. Esseiva, O. Ribaux, C. Weyermann, F. Anglada, S. Lociciro, P. Hayoz, I. Baer, L. Gasté, A.L. Terrettaz-Zufferey, C. Delaporte, P. Margot, Establishment of an operational system for drug profiling: a Swiss experience, Bull. Narc. 57 (2005) 121-147.

[6] W. Eisenberg, A. Tillson, Identification of counterfeit drugs, particularly barbiturates and amphetamines by microscopic, chemical, and instrumental techniques, J. Forensic Sci. 11 (1966) 529-551.

[7] O. Guéniat, P. Esseiva, La comparaison des échantillons d'héroine et de cocaïne à travers la bibliographie, in: O. Guéniat, P. Esseiva (Eds.), Le profilage de l'héroïne et de la cocaïne: une méthodologie moderne de lutte contre le trafic illicite, Presses Polytechniques et Universitaires Romandes (PPUR), Lausanne, 2005, pp. 99-115.

[8] M. Chiarotti, N. Fucci, Comparative analysis of heroin and cocaine seizures, J. Chromatogr. B Biomed. Sci. Appl. 733 (1999) 127-136, https://doi.org/10.1016/ S0378-4347(99)00240-6

[9] V. Dufey, L. Dujourdy, F. Besacier, H. Chaudron, A quick and automated method for profiling heroin samples for tactical intelligence purposes, Forensic Sci. Int. 169 (2007) 108-117, https://doi.org/10.1016/j.forsciint.2006.08.003

[10] P. Esseiva, F. Anglada, L. Dujourdy, F. Taroni, P. Margot, E.D. Pasquier, M. Dawson, C. Roux, P. Doble, Chemical profiling and classification of illicit heroin by principal component analysis, calculation of inter sample correlation and artificial neural networks, Talanta 67 (2005) 360-367, https://doi.org/10.1016/j.talanta. 2005.03.041

[11] P. Esseiva, L. Dujourdy, F. Anglada, F. Taroni, P. Margot, A methodology for illicit heroin seizures comparison in a drug intelligence perspective using large databases, Forensic Sci. Int. 132 (2003) 139-152, https://doi.org/10.1016/S03790738(03)00010-0

[12] I.S. Lurie, C.G. Bailey, D.S. Anex, M.J. Bethea, T.D. McKibben, J.F. Casale, Profiling of impurities in illicit methamphetamine by high-performance liquid chromatography and capillary electrochromatography, J. Chromatogr. A 870 (2000) 53-68, https://doi.org/10.1016/S0021-9673(99)00849-3

[13] M. Morelato, A. Beavis, M. Tahtouh, O. Ribaux, P. Kirkbride, C. Roux, The use of organic and inorganic impurities found in MDMA police seizures in a drug intelligence perspective, Sci. Justice 54 (2014) 32-41, https://doi.org/10.1016/j. scijus.2013.08.006

[14] A.L. Pikkarainen, Systematic approach to the profiling analysis of illicit amphetamine, Forensic Sci. Int. 82 (1996) 141-152, https://doi.org/10.1016/03790738(96)01996-2
[15] C. Weyermann, R. Marquis, C. Delaporte, P. Esseiva, E. Lock, L. Aalberg J.S. Bozenko Jr., S. Dieckmann, L. Dujourdy, F. Zrcek, Drug intelligence based on MDMA tablets data: I. Organic impurities profiling, Forensic Sci. Int. 177 (2008) 11-16, https://doi.org/10.1016/j.forsciint.2007.10.001

[16] L. Cadola, J. Broséus, P. Esseiva, Chemical profiling of different hashish seizures by gas chromatography-mass spectrometry and statistical methodology: a case report, Forensic Sci. Int. 232 (2013) e24-e27, https://doi.org/10.1016/j.forsciint. 2013.08.014

[17] J. Broséus, F. Anglada, P. Esseiva, The differentiation of fibre- and drug type Cannabis seedlings by gas chromatography/mass spectrometry and chemometric tools, Forensic Sci. Int. 200 (2010) 87-92, https://doi.org/10.1016/j. forsciint.2010.03.034

[18] F. Bonadio, P. Margot, O. Delémont, P. Esseiva, Optimization of HS-SPME/GC-MS analysis and its use in the profiling of illicit ecstasy tablets (Part 1), Forensic Sci. Int. 187 (2009) 73-80, https://doi.org/10.1016/j.forsciint.2009.03.004

[19] J.Y.K. Cheng, M.F. Chan, T.W. Chan, M.Y. Hung, Impurity profiling of ecstasy tablets seized in Hong Kong by gas chromatography-mass spectrometry, Forensic Sci. Int. 162 (2006) 87-94, https://doi.org/10.1016/j.forsciint.2006.02.055

[20] L. Dujourdy, V. Dufey, F. Besacier, N. Miano, R. Marquis, E. Lock, L. Aalberg, S. Dieckmann, F. Zrcek, J.S. Bozenko Jr., Drug intelligence based on organic impurities in illicit MA samples, Forensic Sci. Int. 177 (2008) 153-161, https://doi. org/10.1016/j.forsciint.2007.11.013

[21] O. Guéniat, P. Esseiva, Le profilage de l'héroïne et de la cocaïne: une méthodologie moderne de lutte contre le trafic illicite, 1st ed., Presses Polytechniques et Universitaires Romandes (PPUR), Lausanne, 2005.

[22] P. Esseiva, S. Ioset, F. Anglada, L. Gasté, O. Ribaux, P. Margot, A. Gallusser A. Biedermann, Y. Specht, E. Ottinger, Forensic drug Intelligence: an important tool in law enforcement, Forensic Sci. Int. 167 (2007) 247-254, https://doi.org/ 10.1016/j.forsciint.2006.06.032

[23] S. Lociciro, P. Hayoz, P. Esseiva, L. Dujourdy, F. Besacier, P. Margot, Cocaine profiling for strategic intelligence purposes, a cross-border project between France and Switzerland: Part I. Optimisation and harmonisation of the profiling method, Forensic Sci. Int. 167 (2007) 220-228, https://doi.org/10.1016/j.forsciint. 2006.06.052

[24] S. Lociciro, P. Esseiva, P. Hayoz, L. Dujourdy, F. Besacier, P. Margot, Cocaine profiling for strategic intelligence, a cross-border project between France and Switzerland: Part II. Validation of the statistical methodology for the profiling of cocaine, Forensic Sci. Int. 177 (2008) 199-206, https://doi.org/10.1016/j.forsciint. 2007.12.008

[25] S.R. Reddick, European Drug Profiling System (EDPS) feasibility study into the adoption of a European Union (EU) - wide forensic drugs intelligence program for heroin and cocaine, (2011).

[26] D. Corazza, P. Esseiva, L'apport de la trace matérielle dans l'enquête criminelle: Évaluation de la contribution des liens chimiques issus du profilage de produits stupéfiants par l'analyse des réseaux sociaux, Rev. Int. De. Criminol. Et. De. Police Tech. Et. Sci. 66 (2012) 341-363.

[27] M. Morelato, A. Beavis, M. Tahtouh, O. Ribaux, P. Kirkbride, C. Roux, The use of forensic case data in intelligence-led policing: the example of drug profiling, Forensic Sci. Int. 226 (2013) 1-9, https://doi.org/10.1016/j.forsciint.2013.01. 003

[28] N. Stojanovska, S. Fu, M. Tahtouh, T. Kelly, A. Beavis, K.P. Kirkbride, A review of impurity profiling and synthetic route of manufacture of methylamphetamine, 3,4-methylenedioxymethylamphetamine, amphetamine, dimethylamphetamine and p-methoxyamphetamine, Forensic Sci. Int. 224 (2013) 8-26, https://doi.org/ 10.1016/j.forsciint.2012.10.040

[29] J.J. Zacca, É.D. Botelho, M.L. Vieira, F.L.A. Almeida, L.S. Ferreira, A.O. Maldaner, Brazilian Federal Police drug chemical profiling - The PeQui Project, Sci. Justice 54 (2014) 300-306, https://doi.org/10.1016/j.scijus.2014.02.008

[30] R. Marquis, C. Weyermann, C. Delaporte, P. Esseiva, L. Aalberg, F. Besacier J.S. Bozenko Jr., R. Dahlenburg, C. Kopper, F. Zrcek, Drug intelligence based on MDMA tablets data: 2, Phys. Charact. Profil. Forensic Sci. Int. 178 (2008) 34-39, https://doi.org/10.1016/j.forsciint.2008.01.014

[31] M. Bovens, B. Ahrens, I. Alberink, A. Nordgaard, T. Salonen, S. Huhtala Chemometrics in forensic chemistry - Part I: implications to the forensic workflow, Forensic Sci. Int. 301 (2019) 82-90, https://doi.org/10.1016/j.forsciint. 2019.05.030

[32] P. Esseiva, P. Margot, Drug Profiling, in: A. Jamieson, A. Moenssens (Eds.), Wiley Encyclopedia of Forensic Science, John Wiley \& Sons, Ltd, 2009.

[33] N. Gentile, L. Besson, D. Pazos, O. Delémont, P. Esseiva, On the use of IRMS in forensic science: proposals for a methodological approach, Forensic Sci. Int. 212 (2011) 260-271, https://doi.org/10.1016/j.forsciint.2011.07.003

[34] N. Gentile, P. Esseiva, D. Corazza, L. Gasté, J.M. Garcia-Góngora, F. Bonadio Influence of sampling strategy on profiling links: an illustration with two important police operations, 20th ENFSI Drugs Work. Group Meet. Espoo (Finl.) (2014).

[35] M. Morelato, S. Baechler, O. Ribaux, A. Beavis, M. Tahtouh, P. Kirkbride, C. Roux, P. Margot, Forensic intelligence framework - Part I: induction of a transversal model by comparing illicit drugs and false identity documents monitoring, Forensic Sci. Int. 236 (2014) 181-190, https://doi.org/10.1016/j.forsciint.2013.12.045

[36] J. Broséus, S. Baechler, N. Gentile, P. Esseiva, Chemical profiling: a tool to decipher the structure and organisation of illicit drug markets: an 8-year study in Western Switzerland, Forensic Sci. Int. 266 (2016) 18-28, https://doi.org/10. 1016/j.forsciint.2016.04.008

[37] R.E. Bucht, S. Willis, L. Wilson, L. George, M.D. Miranda, Searching for the silver bullet of a unified system to deliver forensic science, american academy of forensic science 73rd annual scientific meeting, Held Virtual (2021). 
[38] B.E. Hayes, Measuring customer satisfaction and loyalty: survey sesign, use and statistical analysis methods, American Society for Quality, 3rd ed., Quality Press, Milwaukee, USA, 2008.

[39] K. Grimmer, A. Bialocerkowski, Surveys, Aust. J. Physiother. 51 (2005) 185-187, https://doi.org/10.1016/S0004-9514(05)70026-X

[40] M.G. Maxfield, E. Babbie, Research Methods for Criminal Justice and Criminology, 6th ed., Wadsworth, Australia, 2011.

[41] E.A. Panacek, Survey-based research: general principles, Air Med. J. 27 (2008) 14-16, https://doi.org/10.1016/j.amj.2007.10.008

[42] S. Beaud, F. Weber, Guide de l'enquête de terrain, Grands Repères, 4th ed., Guides, Paris, 2010.

[43] A. Pires, Échantillonnage et recherche qualitative: essai théorique et méthodologique, in: G. Morin (Ed.), La recherche qualitative. Enjeux épistémologiques et méthodologiques, Poupart, Deslauriers, Groulx, Laperrière, Mayer, Pires, Montréal, 1997, pp. 113-169.
[44] D.R. Thomas, A general inductive approach for analyzing qualitative evaluation data, Am. J. Eval. 27 (2006) 237-246, https://doi.org/10.1177/1098214005283748

[45] M. Blais, S. Martineau, L'analyse inductive générale: description d'une démarche visant à donner un sens à des données brutes, Rech. Qual. 26 (2006) 1-18.

[46] N. Thayer-Hart, N.C. Schaeffer, J. Dykema, K. Elver, Survey fundamentals: A guide to designing and implementing surveys, Office of quality improvement University of Wisconsin-Madison, University of Wisconsin System Board of Regents, Wisconsin, USA, 2010.

[47] L. Dujourdy, G. Barbati, F. Taroni, O. Guéniat, P. Esseiva, F. Anglada, P. Margot, Evaluation of links in heroin seizures, Forensic Sci. Int. 131 (2003) 171-183 https://doi.org/10.1016/S0379-0738(02)00432-2

[48] A. Bolck, C. Weyermann, L. Dujourdy, P. Esseiva, J. van den Berg, Different likelihood ratio approaches to evaluate the strength of evidence of MDMA tablet comparisons, Forensic Sci. Int. 191 (2009) 42-51, https://doi.org/10.1016/j. forsciint.2009.06.006 